\title{
Population genetic structure of Texas horned lizards: implications for reintroduction and captive breeding
}

\author{
Dean A Williams ${ }^{\text {Corresp., } 1}$, Nathan D Rains ${ }^{2}$, Amanda M Hale \\ ${ }^{1}$ Department of Biology, Texas Christian University, Fort Worth, Texas, USA \\ ${ }^{2}$ Texas Parks and Wildlife Department, Cleburne, Texas, USA \\ Corresponding Author: Dean A Williams \\ Email address: dean.williams@tcu.edu
}

The Texas horned lizard (Phrynosoma cornutum) inhabits much of the southern Great Plains of North America. Since the 1950s, this species has been extirpated from much of its eastern range and has suffered declines and local extinctions elsewhere, primarily due to habitat loss. Plans are underway to use captive breeding to produce large numbers of Texas horned lizards for reintroduction into areas that were historically occupied by this species and that currently have suitable habitat. We used mitochondrial markers and nuclear microsatellite markers to determine levels of genetic diversity and population structure in 542 Texas horned lizards sampled from across Texas and some neighboring states to help inform these efforts. Texas horned lizards still retain high genetic diversity in many parts of their current range. We found two highly divergent mitochondrial clades (eastern and western) and three major genetic groupings at nuclear microsatellite loci: a west group corresponding to the western mitochondrial clade and north and south groups within the eastern mitochondrial clade. We also found some evidence for human-mediated movement between these genetic clusters that is probably related to the historical importance of this species in the pet trade and as an iconic symbol of the southwestern United States. We do not know, however, if there are fitness costs associated with admixture (especially for the western and eastern clades) or if there are fitness costs to moving these lizards into habitats that are distinctly different from their ancestral areas. If present, either one or both of these fitness costs would decrease the effectiveness of reintroduction efforts. We therefore recommend that reintroduction efforts should maintain current genetic structure by restricting breeding to be between individuals within their respective genetic clusters, and by reintroducing individuals only into those areas that encompass their respective genetic clusters. This cautionary approach is based on the strong divergence between genetic groupings and their correspondence to different ecoregions. 
1 Population genetic structure of Texas horned lizards: implications for

2 reintroduction and captive breeding

3

4 Dean A. Williams ${ }^{1}$, Nathan D. Rains ${ }^{2}$, and Amanda M. Hale ${ }^{1}$

$5{ }^{1}$ Department of Biology, Texas Christian University, Fort Worth, Texas 76129, USA

$6 \quad{ }^{2}$ Texas Parks and Wildlife Department, Cleburne, Texas, 76033, USA

7 Corresponding Author:

8 Dean Williams ${ }^{1}$

9 Department of Biology, Texas Christian University, 2955 S. University Dr., Fort Worth, Texas

1076129, USA

11 Email address: dean.williams@tcu.edu 


\section{Abstract}

14 The Texas horned lizard (Phrynosoma cornutum) inhabits much of the southern Great Plains of

15 North America. Since the 1950s, this species has been extirpated from much of its eastern range

16 and has suffered declines and local extinctions elsewhere, primarily due to habitat loss. Plans are

17 underway to use captive breeding to produce large numbers of Texas horned lizards for

reintroduction into areas that were historically occupied by this species and that currently have

suitable habitat. We used mitochondrial markers and nuclear microsatellite markers to determine

levels of genetic diversity and population structure in 542 Texas horned lizards sampled from across Texas and some neighboring states to help inform these efforts. Texas horned lizards still retain high genetic diversity in many parts of their current range. We found two highly divergent mitochondrial clades (eastern and western) and three major genetic groupings at nuclear microsatellite loci: a west group corresponding to the western mitochondrial clade and north and south groups within the eastern mitochondrial clade. We also found some evidence for humanmediated movement between these genetic clusters that is probably related to the historical importance of this species in the pet trade and as an iconic symbol of the southwestern United States. We do not know, however, if there are fitness costs associated with admixture (especially for the western and eastern clades) or if there are fitness costs to moving these lizards into habitats that are distinctly different from their ancestral areas. If present, either one or both of

31 these fitness costs would decrease the effectiveness of reintroduction efforts. We therefore recommend that reintroduction efforts should maintain current genetic structure by restricting breeding to be between individuals within their respective genetic clusters, and by reintroducing

34 individuals only into those areas that encompass their respective genetic clusters. This cautionary 
35 approach is based on the strong divergence between genetic groupings and their correspondence

36 to different ecoregions.

37

38 Keywords

39 Genetic diversity, microsatellite loci, mitochondrial, conservation 
40

41 The loss of suitable native habitat to agriculture and urbanization, and the overexploitation of populations have been the largest drivers of the decline of many species (Maxwell et al., 2016).

As a result of these and other anthropogenic factors, populations become small and highly fragmented, further endangering species persistence due to stochastic demographic and genetic effects (Frankham, Ballou \& Briscoe, 2010). Reintroduction and reinforcement programs try to reduce these effects by returning a species to an area from which it became locally extinct or by increasing the numbers of individuals in small populations (IUCN, 2013; Seddon, 2010). A sufficient number of individuals with high genetic diversity should be utilized in these efforts to reduce the potential for inbreeding depression and enhance the ability of a population to adapt to changing environmental conditions (Johnson et al., 2010; Carlson, Cunningham \& Westley, 2014; Jamieson, 2015). Reintroduction success can be increased by releasing individuals that are matched ecologically and genetically to the introduction region (Houde et al., 2015; Marr et al., 2018). Additionally, it may also be advisable to prevent mixing of individuals from populations that are ecologically and genetically divergent, to reduce the chances of outbreeding depression (Frankham et al., 2011; Weeks et al., 2011). Captive breeding programs can potentially be used to raise large numbers of individuals for these reintroduction efforts and are subject to many of the same genetic considerations as reintroductions (Ebenhard, 1995; Williams \& Osentoski, 2007; Attard et al., 2016). Understanding the population genetic structure of a species can inform these efforts by identifying appropriate source populations, defining management units, and identifying populations that have high genetic diversity (Weeks et al., 2011; Attard et al., 2016). Texas horned lizards (Phrynosoma cornutum) belong to a specialized group of lizards (Phrynosoma) that are endemic to North America. They have a variety of adaptations for living 
63 in dry environments and for specializing on a diet of large venomous ants (e.g. Pogonomyrmex

64 spp.; Sherbrooke, 2003). Texas horned lizards have an extensive range in North America and

65

66

67

cover a number of different ecoregions (Price, 1990). Very little genetic work has been

conducted on this species, although several studies have found two distinct mitochondrial clades that correspond to a more western clade in New Mexico and Arizona and an eastern clade in Texas (Guerra, 1998; Rosenthal \& Forstner, 2014). The geographic extent of these clades is not clear, however, due to a lack of comprehensive sampling in past studies. Texas horned lizards are generally sedentary and aspects of their life history and anatomy suggest dispersal is relatively limited (Sherbrooke, 2003), which could result in strong population structure for this species. On the other hand, anecdotal accounts suggest that these lizards have been moved extensively by the pet trade and individual collectors (Price, 1990), leading to more population homogenization than might be expected from natural dispersal.

Within Texas, the species was historically found in nine of ten ecoregions (United States Environmental Protection Agency (EPA) Ecoregions of the U.S. - Level III) and anecdotal accounts suggest it was abundant in many areas (Price, 1990; Donaldson, Price \& Morse, 1994). Declines in Texas began to be noticed between 1950 and 1970, and the species has since disappeared from much of its eastern range with decreases in abundance and local extinctions reported for other areas (Price, 1990; Donaldson, Price \& Morse, 1994; Henke, 2003). The major reason for the declines is most likely the loss of suitable habitat due to agriculture and urbanization (Donaldson, Price \& Morse, 1994). Other possible factors include the introduction of red fire ants (Solenopsis invicta) which can prey on the eggs and young of horned lizards, the loss of harvester ants (Pogonomyrmex spp.) due to widespread use of insecticides and competition with fire ants, and over-collecting for the pet and curio trades (Price, 1990; 
86 Donaldson, Price \& Morse, 1994). Currently the species is listed as threatened in Texas due to

87 the declines, but globally it is classified as least concern by the IUCN since the species is still

88 common in the more western and southern parts of its range (Hammerson, 2007).

89 Widespread interest by private landowners and the Texas Parks and Wildife Department

90 has led to a plan in which Texas zoos will captive breed large numbers of individuals to be

91 reintroduced into areas that historically had Texas horned lizards and that currently have suitable

92 habitat. To aid in this effort, we used mitochondrial markers and nuclear microsatellite markers

93 to determine levels of genetic diversity and population structure of Texas horned lizards across

94 Texas and some neighboring states. Species like Texas horned lizards, which occur over large

95 geographic areas, inhabit a range of habitats, and have relatively low dispersal capabilities may

96 have an increased chance of developing regional adaptations (Lenormand, 2002). We therefore

97 also ask if genetic subdivisions are related to ecoregions, which could potentially indicate the

98 presence of regionally-adapted units. These results will be used to determine the most

99 appropriate source populations for reintroduction efforts and to provide recommendations for

100 how captive populations should be managed. The neutral genetic patterns described in this study

101 will also help inform future planned studies of adaptive genetic diversity in this species.

103 Materials \& Methods

\section{Sampling and DNA extraction}

105 A number of volunteers collected 542 Texas horned lizard tissue samples across Texas, New

106 Mexico, and Colorado between 2009 and 2017 (Fig. 1). While most of these samples were

107 collected using the cloacal swab method described in Williams et al. (2012), some were from

108 tissues collected from road kill and toe clips collected as part of other population studies. Field 
109 activities were approved by Texas Parks and Wildlife Department (SPR-1006-763). Texas

110 Christian University Institutional Animal Care and Use Committee (IACUC) provided approval

111 for this research (protocol 01/08). Samples were mapped onto EPA level II and III ecoregions

112 using ArcGIS Pro and each sample was classified as belonging to a specific ecoregion

113 (Omernick, 1987; 1995; Omernick \& Griffith, 2014) (https://www.epa.gov/eco-

114 research/ecoregions).

115 We extracted DNA by incubating swabs and tail or toe clips overnight in $300 \mu 1$ lysis

116 buffer and $15 \mu \mathrm{l}$ of Proteinase $\mathrm{K}(20 \mathrm{mg} / \mathrm{ml})$ at $55^{\circ} \mathrm{C}$. The following day, a half volume of $7.5 \mathrm{M}$

117 ammonium acetate was added to precipitate proteins. Then 0.7 volume of isopropanol was added

118 to the supernatant and the samples were placed at $-20^{\circ} \mathrm{C}$ overnight to precipitate the DNA.

119 Finally, DNA was pelleted and washed in 70\% ethanol, air dried, and resuspended in $100 \mu 10$

$120 \mathrm{mM}$ Tris $\mathrm{pH} 8.5$.

121 Genotyping and sequencing

122 We amplified 10 microsatellite loci in three multiplexes using $10 \mu$ polymerase chain reactions

123 (PCR; Williams et al., 2012). Four loci (PcGATA49, PcGATA61, PcGATA60, PcGATA31)

124 reported in Williams et al. (2012) gave evidence of high levels of null alleles in multiple

125 populations, or problems with large allele dropout (PcGATA 49) and so are not included in this

126 study. PCR reactions contained 10-50 ng DNA, $0.2 \mu \mathrm{M}$ of each primer, 1X Qiagen Multiplex

127 PCR Master Mix with HotStarTaq, Multiplex PCR buffer with 3mM $\mathrm{MgCl}_{2} \mathrm{pH}$ 8.7, and dNTPs.

128 Reactions were cycled in an ABI 2720 thermal cycler (ThermoFisher Scientific, Waltham,

129 Massachusetts, USA). The cycling parameters were one cycle at $95^{\circ} \mathrm{C}$ for $15 \mathrm{~min}$; followed by

13035 cycles of $30 \mathrm{~s}$ at $94^{\circ} \mathrm{C}, 90 \mathrm{~s}$ at $60^{\circ} \mathrm{C}, 90 \mathrm{~s}$ at $72^{\circ} \mathrm{C}$; then a final extension at $60^{\circ} \mathrm{C}$ for $30 \mathrm{~min}$.

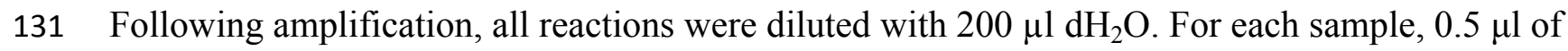


132 diluted product was loaded in $10 \mu \mathrm{l}$ HIDI formamide with $0.1 \mu \mathrm{LIZ}-600$ size standard

133 (ThermoFisher Scientific, Waltham, Massachusetts, USA) and electrophoresed on an ABI

134 3130XL Genetic Analyzer (ThermoFisher Scientific, Waltham, Massachusetts, USA). Genotypes

135 were scored and binned using Genemapper 5.0 (ThermoFisher Scientific, Waltham,

136 Massachusetts, USA). We reamplified a subset of samples $(\sim 10 \%, \mathrm{n}=55$ individuals $)$ to

137 estimate the genotyping error rate.

138 We amplified a $353 \mathrm{bp}$ fragment near the 5' end of the mitochondrial control region using 139 primers PcCR F - CTTATGATGGCGGGTTGCT and PcCR R -

140 GGCTGTTAAATTTATCCTCTGGTG for all 542 individuals. We also amplified the

141 mitochondrial NADH dehydrogenase subunit 4 (ND4) and the tRNAs Histidine, Serine, and

142 Leucine region using the primers ND4 - ACCTATGACTACCAAAAGCTCATGTAGAAGC

143 and Leu - CATTACTTTTACTTGGATTTGCACCA from Arèvalo, Davis \& Sites (1994) in 49

144 individuals from across the sampled range. PCR reactions contained 10-50 ng DNA, $0.25 \mu \mathrm{M}$ of

145 each primer, 1X Qiagen Multiplex PCR Master Mix with HotStarTaq, Multiplex PCR buffer

146 with $3 \mathrm{mM} \mathrm{MgCl}_{2} \mathrm{pH} 8.7$, and dNTPs. Reactions were cycled in an ABI 2720 thermal cycler.

147 The cycling parameters were one cycle at $95^{\circ} \mathrm{C}$ for $15 \mathrm{~min}$; followed by 35 cycles of $30 \mathrm{~s}$ at

$14894^{\circ} \mathrm{C}, 15 \mathrm{~s}$ at $55^{\circ} \mathrm{C}, 30 \mathrm{~s}$ at $72^{\circ} \mathrm{C}$; then a final extension at $72^{\circ} \mathrm{C}$ for $5 \mathrm{~min}$. Reactions were cleaned

149 enzymatically with ExoI and rSAP using the manufacturer's protocols (New England Biolabs

150 Ipswich, Massachusetts, USA). Products were sequenced in both directions using PCR primers

151 and internal primer ND4\#2 - TACGACAAACAGACCTAAAATC from Arèvalo, Davis \& Sites

152 (1994) for ND4 and electrophoresed on an ABI 3130XL Genetic Analyzer. Sequences were

153 trimmed, edited, and put into contigs using Sequencher 4.8 (Gene Codes Corporation, Ann

154 Arbor, MI USA). Sequences were aligned in MEGA 10 (Kumar et al., 2018) using Clustal W 
155 (Thompson, Higgins \& Gibson 1994). All unique sequences have been deposited in GenBank

156 (accession numbers: MK100594 - MK100710).

157 Microsatellite genotype analyses

158 The cryptic nature and low density of Texas horned lizards in most places made it difficult to

159 find large numbers of individuals from single localities. To calculate traditional genetic diversity

160 metrics, however, we grouped 449 of the 542 horned lizards into 16 sampling sites with $\geq 10$

161 individuals in each (Table 1, Fig. 2). We grouped lizards into these sites because we were

162 interested in estimating the genetic diversity present in protected areas such as Wildlife

163 Management Areas and State Parks where individuals might be captured for future captive

164 breeding purposes. In addition to these nine protected areas, we also chose seven other areas

165 such as counties with $\geq 10$ sampled lizards, to increase our number of sampling sites to test for

166 isolation-by-distance. The coordinates for these sites were the centroids of the sampled lizard

167 locations. For these 16 sites, we used GenAlEx 6.5 (Peakall \& Smouse, 2006; 2012) to calculate

168 observed $\left(\mathrm{H}_{\mathrm{O}}\right)$ and expected heterozygosity $\left(\mathrm{H}_{\mathrm{E}}\right)$ and $\mathrm{F}_{\mathrm{IS}}$. We used HP-RARE (Kalinowski,

$1692005)$ to calculate allelic richness $\left(A_{R}\right)$ at each site to standardize comparisons across sample

170 sizes. We tested for heterozygote excess and deficiencies and genotypic linkage disequilibrium

171 using GENEPOP 4.0 (Rousset, 2008). We used sequential Bonferroni correction to determine

172 significance for these tests. MICRO-CHECKER 2.2.3 (Van Oosterhout et al., 2004) was used to

173 determine the presence of null alleles, large allele dropout, or issues with scoring due to

174 stuttering and to calculate null allele frequencies (Brookfield, 1996 eq1). As there was some

175 evidence of null alleles, we used the ENA correction method from Chapuis and Estoup (2007)

176 implemented in the software FreeNA to calculate global and pairwise $\mathrm{F}_{\mathrm{ST}}$. We used these

177 corrected values to test for isolation-by-distance using the Mantel test in GenAlEx. Because the 
178 magnitude of $\mathrm{F}_{\mathrm{ST}}$ is influenced by heterozygosity, we also present the standardized measure $\mathrm{F}^{\prime}$ 'ST

179 developed by Meirmans \& Hedrick (2011). We also used a principal component analysis (PCA)

180 in GenAlEx to visualize the pattern of pairwise F' ${ }_{\text {ST }}$ between sampling sites and compared these

181 to the STRUCTURE results (see below) which utilized all samples.

182 We used STRUCTURE 2.3.4 (Pritchard, Stephens \& Donnelly, 2000) to cluster

183 multilocus genotypes from all 542 samples, including those not found within the 16 sampling

184 locations mentioned above. We assumed admixture and correlated allele frequencies with no

185 location prior and set the burn-in to $10^{4}$ iterations and ran the MCMC (Monte Carlo Markov

186 Chain) for $10^{6}$ iterations. STRUCTURE can give misleading results both for the number of

187 populations and individual ancestry if there is uneven sampling across clusters (K; Puechmaille,

188 2016; Wang, 2017). We used the recommendations of Wang (2017) and set the prior for

189 admixture to allow $\alpha$ to vary between clusters and we decreased the initial $\alpha$ from 1.0 to 0.2 . We

190 ran ten independent runs for $\mathrm{K}=1$ to 10 . The most likely $\mathrm{K}$ was identified using the method of

191 Evanno, Regnaut, and Goudet (2005) and by determining the K with the highest LnP(D) before

192 values started to plateau (Pritchard, Stephens \& Donnelly, 2000). We then used CLUMPP 1.1.1

193 (Jakobsson \& Rosenberg, 2007) to average across the ten runs for the most likely K. We

194 considered individuals to be admixed between clusters when their ancestry (q) was $\geq 0.10$ in

195 each of two or more clusters. We chose this value since similar cut-off values have been used in

196 a number of other studies (Barilani et al., 2005; Vähä \& Primmer, 2006; Sanz et al., 2009;

197 Bohling et al., 2013; Johnson et al. 2015). The null alleles we found in this study are not

198 expected to impact the accuracy of these assignments given the very small difference in $\mathrm{F}_{\mathrm{ST}}$

199 values after correction (see results) and because simulation studies have found only a slight 
200 reduction in the power of assignment tests in the presence of null alleles (Carlsson, 2008; Marsh

201 et al., 2008).

\section{Mitochondrial sequence analyses}

203 We used GenAlEx to calculate the frequency of haplotypes and haplotype diversity $(h)$ of the 204 control region for the 16 sampling sites mentioned above. We used CONTRIB 1.02 (Petit,

205 Mousadik \& Pons, 1998) to calculate haplotype richness $\left(\mathrm{H}_{\mathrm{R}}\right)$ at each site. We compared mtDNA 206 population structure for these 16 sites to the nuclear microsatellite structure by calculating $\phi_{\mathrm{PT}}$

207 for both data sets and conducting AMOVAs in GenAlEx.

208 We constructed single gene trees for both ND4 and the control region due to the difference in sampling for each marker. The model for nucleotide substitution was that with the highest value of the Bayesian information criterion (BIC) in MEGA. The resulting models were $\mathrm{HKY}+\mathrm{G}$ for ND4 and HKY $+\mathrm{G}+\mathrm{I}$ for the control region. These models were then used to create maximum likelihood trees in MEGA using the nearest-neighbor-interchange and a strong branch swap filter. Bootstrap values were calculated using 1,000 replicates. Phrynosoma asio (JN809342.1) was used to root the ND4 gene tree and Phrynosoma blainvillii (NC_036492.1) was used to root the control region tree. Bayesian analyses using MrBayes 3.2 (Huelsenbeck \& began with two parallel runs with random starting trees and were run for $2 \times 10^{7}$ generations and sampled every $10^{3}$ generations. Burn-in was the first $25 \%$ of generations and a $50 \%$ majority rule consensus tree was calculated. 
223 DnaSP 6.11.01 (Rozas et al., 2017) to calculate the frequency of haplotypes, haplotype diversity

$224(h)$, nucleotide diversity $(\pi)$, and $\Theta$ (Watterson's estimator). We also conducted neutrality tests in 225 DnaSP, including Tajima's D (Tajima, 1989) and Fu's $F_{S}(F u, 1997)$ to compare the number of 226 rare and common mutations to the null hypothesis of a stable population, in contrast to an 227 expectation of an excess of low frequency mutations following rapid population growth. When D 228 and $F_{S}$ were significantly different from neutral expectations for the ND4 data, we used the 229 mismatch distribution to estimate the time since population growth, tau $(\tau)$ as $\tau=2 \mu \mathrm{kt}$, where $\mathrm{t}$ is 230 the time in generations, $\mu$ is the mutation rate per site per generation, and $\mathrm{k}$ is the sequence 231 length (Rogers, 1995). We calculated tau in Arlequin 3.5.1.3 (Excoffier \& Lischer, 2010). We 232 assumed a generation time of two years (Ballinger, 1974), and used an online calculator to 233 calculate time since population growth (Schenekar \& Weiss, 2011). We used a substitution rate 234 of 0.00805 (substitutions/site/million years) which was estimated for ND4 in geckos (Macey et 235 al., 1999) and used by Blair and Bryson (2017) in their study of species delimitation in 236 Phrynosoma.

\section{Results}

Microsatellite data

Most loci across the 16 sampling sites were in Hardy-Weinberg equilibrium and all loci were in genotypic linkage equilibrium. There was one locus/site comparison (out of 160) that had a significant heterozygote deficit after sequential Bonferroni correction. In addition to this one

243 comparison, MICRO-CHECKER also identified five other loci/site comparisons that had null 244 alleles (Table S1). There were four loci that gave evidence of null alleles at one site each and 245 another locus that had evidence for null alleles at two sites (Table S1). There were a total of 19 
246 individual/locus non-amplifications in the entire dataset, spread across six of the loci. We found

247 eight allele errors across 1,140 alleles in the 55 individuals we re-genotyped for an error rate of

248 0.007. These errors occurred across five loci (per locus error rates for these five loci ranged from

2490.009 to 0.018$)$. A total of seven samples (12\%) had one allele error each.

250 Genetic diversity was generally high (mean $\pm \mathrm{SE}: \mathrm{H}_{\mathrm{E}}=0.83 \pm 0.006, \mathrm{~A}_{\mathrm{R}}=8.47 \pm 0.18, \mathrm{n}$

$251=16$ sampling sites) and similar across sites, with the exception of the population on Matagorda

252 Island which had lower heterozygosity and allelic richness than mainland sites (Table 1). We

253 corrected for null alleles when calculating $\mathrm{F}_{\mathrm{ST}}$; however, this made virtually no difference in the

254 observed patterns ( $\mathrm{F}_{\mathrm{ST}}$ values generally only decreased by 0.001$)$. Population differentiation was

255 modest but significant with a global $\mathrm{F}_{\mathrm{ST}}$ of $0.044(95 \% \mathrm{CI} 0.033-0.061)$ and pairwise $\mathrm{F}_{\mathrm{ST}}$

256 ranging from 0.003 to 0.115 (Tables S2 and S3). Standardized values were much higher with a

257 global F' ${ }_{\text {ST }}$ of 0.302 and pairwise values ranging from 0.011 to 0.665 . The first two axes of the

258 PCA of pairwise $\mathrm{F}_{\text {ST }}$ explained $52.4 \%$ of the variance and revealed a tight cluster of 11 sites

259 (RPQRR, Midland Co., CMA, Yoakum Dunes WMA, Matador WMA, Seminole Canyon SP,

260 Grey Co., Mitchell Co., Camp Bowie, Colorado, E. New Mexico) and two other more separated

261 sets of sites (Chaparral WMA, Starr Co., Matagorda Island WMA) and (Brewster Co., Hueco

262 Tanks SP; Fig. 3). Most pairwise $\mathrm{F}_{\mathrm{ST}}$ comparisons were significantly different from zero except

263 for 23 comparisons which were all between sites within the cluster of 11 sites in the PCA (Table

264 S2). There was a significant pattern of isolation-by-distance for all 16 sampling sites $\left(\mathrm{R}^{2}=0.33\right.$,

$265 \mathrm{P}=0.003)$ and for the 11 sampling sites that formed the tight cluster in the PCA $\left(\mathrm{R}^{2}=0.24, \mathrm{P}=\right.$ 266 0.02).

The STRUCTURE analysis using all samples revealed three major genetic clusters or

268 populations, both using the Evanno, Regnaut, and Goudet (2005) method and the LnP(D) method 
269 of Pritchard, Stephens, and Donnelly (2000; Fig. S1). At K = 3, samples were partitioned into

270 west, north, and south populations (Fig. 4). At increasing levels of K (4-10), new clusters were

271 simply added as admixture in the large north population. Sub-clustering the south population

272 produced a split between Matagorda Island WMA and the mainland (Fig. S2). Sub-clustering the

273 west population revealed two clusters, one composed of west individuals and another population

274 from Brewster Co. around the Elephant Mountain WMA (Site \#1 in Fig. 2, Fig. S2). Most of the

275 individuals $(83 \% ; 25$ of 30$)$ assigned to the west sub-population had western clade haplotypes

276 (see mitochondrial section below), whereas most of the individuals $(95 \% ; 21$ of 22 ) assigned to

277 the Elephant Mountain WMA sub-population had eastern clade mitochondrial haplotypes. Sub-

278 clustering the north population did not reveal more populations. The north, south, and west

279 populations found by the STRUCTURE analyses were concordant with the pattern of pairwise

280 population $\mathrm{F}_{\text {ST }}$ seen in the PCA. The 11 sites that clustered close together all belonged to the

281 north population, whereas the Chaparral WMA, Starr Co. and Matagorda Island WMA belonged

282 to the south population. Hueco Tanks SP was assigned to the west population and Brewster Co.,

283 which fell between the northern population and Hueco Tanks SP in the PCA, had individuals

284 assigned to north and west populations and individuals that were admixed between the

285 populations.

286 The west population is found within the Chihuahua Deserts and Madrean Archipelago

287 ecoregions and the south population is found south of the Balcones Escarpment in the Southern

288 Texas Plains, East-Central Texas Plains, and Western Gulf Coastal Plain ecoregions (Table 2,

289 Fig. 1). The north population is found north and north-west of the Balcones Escarpment within a

290 number of level III ecoregions including the High Plains, Central Great Plains, Southwestern

291 Tablelands, Edwards Plateau, and Cross Timbers which collectively belong to the level II South- 
292 Central Semi-Arid Prairies ecoregion (Table 2, Fig. 1). Some individuals with genotypes from

293 the north population ( $\mathrm{n}=28$ individuals) also occurred in the Chihuahua Deserts ecoregion in

294 Texas. There were two individuals that had high $(\mathrm{q}>0.90)$ ancestry assignment in the north

295 population but were found in the South Texas Plains, and one individual with high ancestry

296 assignment in the south population that was found in the Central Great Plains ecoregion.

297 Most individuals (90\%; 486 of 542) were strongly assigned to a single population. The

298 remaining individuals $(10 \%$; 56 of 542) had evidence of admixture. Admixture between the

299 south and north populations ( $\mathrm{n}=41$ of 488 individuals) was more common than between west

300 and north populations ( $\mathrm{n}=13$ of 421 individuals; Fisher exact test, $\mathrm{P}=0.001)$. The remaining

301 two individuals were admixed between all three populations; one was found in southern Texas

302 whereas the other was found in northern Texas. Admixed individuals with north and west

303 ancestry were found in Brewster Co. where the north and west populations meet $(\mathrm{n}=4$

304 individuals) and in widely separated areas including Colorado $(\mathrm{n}=4)$, Seminole Canyon SP $(\mathrm{n}=$

305 3), Matador WMA $(\mathrm{n}=1)$, Yoakum Dunes WMA $(\mathrm{n}=1)$, CMA $(\mathrm{n}=1)$, and Starr Co. $(\mathrm{n}=1)$.

306 Admixed individuals with north and south ancestry were found south of the Balcones

307 Escarpment $(n=14)$ in the south population and far north of the Escarpment $(n=27)$ in the north

308 population.

309 Mitochondrial data

310 Haplotype diversity at the control region was high with a total of 86 haplotypes found across all

311542 individuals. Haplotype diversity $(h)$ and richness was more variable between the 16 sites

312 than microsatellite diversity (Table 1, 3). For instance, Midland, Yoakum Dunes WMA, and

313 RPQRR had relatively low haplotype diversity and richness compared to their microsatellite

314 diversities. Despite the variability in mitochondrial diversity there was a positive correlation 
315 between haplotype richness and allelic richness $\left(r_{S}=0.57, P=0.02\right)$. Population subdivision was

316 considerably higher for the mtDNA control region than for the microsatellite loci with $32 \%$ of

317 the variance between sites for the control region $\left(\phi_{\mathrm{PT}}=0.32, \mathrm{AMOVA}, \mathrm{P}=0.001\right)$ and $8 \%$ of the

318 variance between sites for the microsatellite loci $\left(\phi_{\mathrm{PT}}=0.08, \mathrm{AMOVA}, \mathrm{P}=0.001\right)$.

319 The control region gene tree revealed two clades between haplotypes found in western

320

321

322

323

324

325

326

327

328

329

330

331

332

333

334

335

336

337

areas (New Mexico and far western Texas) and more eastern areas (Fig. 5). The western clade was well supported in this analysis $(\mathrm{bs}=80)$. For the control region, there were a total of ten unique haplotypes in the western clade and 76 haplotypes in the eastern clade. There was an average of $3.91 \%$ divergence between the clades (range: $2.01-5.31 \%$ ), 1.43\% divergence within the eastern clade (range: $0.28-2.92 \%$ ), and $0.08 \%$ divergence within the western clade (range: 0.28-1.72\%). P. cornutum differed from P. blainvillii by $12.40 \%$ (range: $11.31-13.74 \%$ ). The western haplotypes mainly belonged to individuals with high microsatellite ancestry in the west population (mean $\pm \mathrm{SE}$ q: $0.97 \pm 0.003, \mathrm{n}=28$ ), with the exception of two individuals that had high north ancestry $(q=0.99)$ and were found in Brewster Co. Within Brewster Co., there were also 21 individuals with high west ancestry $(q>0.90)$ that had eastern haplotypes, indicating that this region is an area of admixture between the western and eastern mitochondrial clades. We found no evidence for separate mitochondrial clades corresponding to the north and south populations detected by STRUCTURE. Individuals with the eastern haplotypes had microsatellite ancestry within the north, south, and west populations. Control region haplotypes were, however, largely unique to the geographic regions encompassed by the three main nuclear microsatellite populations (west, north, and south) as indicated by the colored symbols in Fig. 5 .

Only seven of the 86 haplotypes were shared between regions. The south region had the highest haplotype diversity $(h=0.90)$, followed by the west $(h=0.88)$, and then the north region $(h=$ 
338 0.72). To compare the three regions, we used the standardized estimate of $\phi \mathrm{PT}$ using the method

339 of Hedrick to ensure that $\phi \mathrm{PT}=1.0$ when populations have non-overlapping sets of haplotypes

340 (Meirmans \& Hedrick, 2011). $\$ \mathrm{PT}$ was $0.97(\mathrm{P}=0.001)$ among the three regions, reflecting the

341 low sharing of haplotypes between them.

342

The ND4 gene tree also revealed two well-supported clades between haplotypes found in

343

344

345

346

347

348

349

350

351

352

353

354

355

356

357

358

359

360

western areas (New Mexico and far western Texas) and more eastern areas (Fig. 6). Both the

maximum likelihood and Bayesian analyses recovered the same tree topology. There were a total of ten unique haplotypes in the western clade and 21 unique haplotypes in the eastern clade.

There was an average of $7.07 \%$ divergence between the clades (range: $6.50-7.80 \%), 0.07 \%$

divergence within the eastern clade (range: $0.10-1.70 \%$ ), and $0.04 \%$ divergence within the western clade (range: $0.10-0.60 \%$ ). P. cornutum differed from $P$. asio by $16.40 \%$ (range: $15.80-$

$16.80 \%$ ). Similar to the control region, the western clade comprised individuals with high

microsatellite ancestry in the west population. Similar to the control region, we did not find separate clades for the ND4 gene that corresponded to the north and south populations detected by STRUCTURE.

Using all samples sequenced for the ND4 region and a subset of samples sequenced for the control region (same samples as the ND4 region plus all western clade samples), haplotype diversity and sequence diversity were higher for the eastern clade than the western clade (Table 4). This result is consistent with the larger geographic range of the eastern clade and the higher effective population size of the eastern clade as indicated by larger theta values (Table 4). We found evidence for past population expansions for both clades; Fu's $F_{S}$ was significantly negative $(\mathrm{P}<0.05)$ relative to neutral expectations for both western and eastern clades of ND4 and the control region. Tajima's D was significantly negative $(\mathrm{P}<0.05)$ only for the ND4 data 
361 (Table 4). Using the data from the ND4 region, the time of expansion was estimated to be

362151,288 years ago for the western clade and 467,196 years ago for the eastern clade.

364 Discussion

365 With the exception of the Matagorda Island population, the Texas horned lizard sampling

366 localities included in this study harbor high levels of genetic variation and would therefore

367 provide suitable source individuals for captive breeding and reintroduction efforts. Across the

368 surveyed area, Texas horned lizards exhibit two major groupings at mtDNA loci (western and

369 eastern) and three major genetic groupings at nuclear loci (west, north, and south). These major

370 genetic patterns should be used to inform both captive breeding and reintroduction strategies for

371 this species.

372 The major genetic groupings were found in ecoregions which differ from each other in

373 patterns of precipitation, temperature, and vegetation (Griffith et al., 2007). The western

374 mitochondrial clade and population is found in the Chihuahua desert ecoregion, whereas the

375 eastern mitochondrial clade can be subdivided into two nuclear DNA populations that

376 correspond to a north cluster found in the South-Central Semi-Arid Prairies ecoregion (EPA

377 level II) and a south cluster found in the South Texas Plains, East-Central Texas Plains, and

378 Western Gulf Coastal Plain. The Chihuahua desert ecoregion (west clade) is an area of high

379 biodiversity and endemism. The vegetation is predominantly semi-desert grassland and

380 shrubland, with a single rainy season during the summer (late June-October). Precipitation is

381 lower than in the other ecoregions. The South-Central Semi-Arid Prairies ecoregion (northern

382 cluster) encompasses five level III ecoregions and is composed of tall and short grass prairies.

383 Precipitation varies across this region from very low in the High Plains ecoregion to higher 
384 precipitation in the Central Plains and Cross Timbers ecoregions. These ecoregions can

385

386

387

388

389

390

391

392

393

394

experience strong seasonality in temperatures, with colder and longer winters, especially in the more northern areas. The South Texas Plains, East-Central Texas Plains, and Western Gulf Coastal Plains (south cluster) are lower in elevation and have a subtropical climate with mild winters and a pattern of bimodal precipitation occurring in the spring and fall. Thorny brush and coastal grasslands are the predominant vegetation types. Differences in vegetation, precipitation, and temperature between the ecoregions suggest that studies of behavioral differences (e.g. diet and activity budgets), morphological differences important for predator avoidance (e.g. coloration, length of horns) or water regulation (e.g. overall body size, scale size), and physiology (e.g. thermal tolerance, water balance) should be conducted between and within these clusters to determine the presence and scale of potential adaptations in this species.

The eastern and western mitochondrial split in Texas horned lizards was consistent with some previous studies (Guerra, 1998; Rosenthal \& Forstner, 2014), although the eastern extent of the western clade was not clear in these studies due to a lack of sampling in south-western Texas. The presence of a late Pliocene pluvial lake, Lake Cabeza de Vaca, which covered up to 23,000$26,000 \mathrm{~km}^{2}$ in southern New Mexico, far western Texas, and Mexico has been hypothesized as the barrier that originally separated these two clades (Guerra, 1998; Rosenthal \& Forstner, 2014). A number of amphibian, reptile, and mammal species have their eastern or western range limitations in the region of the lake as well as evidence for species or subspecies differentiation on either side of the lake region (Axtell, 1977). Phylogenetic studies have also found high divergence on either side of the lake region for several reptile species (Rosenthal \& Forstner, 2014). The lake system started to drain in the mid-Pleistocene ( 750,000 years ago; Strain, 1966 ; Reeves, $1965 ; 1969)$. The estimated time of expansion that we found for the western clade of the 
407 Texas horned lizard occurred later in the mid-Pleistocene (151,288 years ago) which may have

408 then spread into far western Texas where it occurs today. The eastern clade's expansion was also

409 estimated to have begun in the middle Pleistocene, but the timing was a few hundred thousand

410 years earlier than what was estimated for the western clade. The higher haplotype diversity found

411 in the south region may indicate that it was the source for expansion into more northern areas.

412 We recommend that the western and eastern populations, as identified by the

413 mitochondrial analyses presented here, should be considered separate evolutionary significant

414 units (ESUs; Moritz, 1994; Crandall et al., 2000). There is reciprocal monophyly and high

415 divergence between the mitochondrial western and eastern clades that is also broadly concordant

416 with the nuclear microsatellite data. The western group is also confined to the Chihuahua desert

417 ecoregion which represents a much different habitat than what is inhabited by most individuals

418 from the more eastern group. The mtDNA genetic distance between these clades (7\%) is much

419 higher than within-clade distances and may indicate either subspecies or species differences

420 (Guerra, 1998; Rosenthal \& Forstner, 2014). Nonetheless, the presence of admixed individuals in

421 this dataset provide some evidence for hybridization between horned lizards from the western

422 and eastern groupings. This result, in conjunction with evidence that the two clades successfully

423 hybridize in captive breeding programs in zoos (Williams, 2018, personal observations) might

424 argue against separate full species designations for eastern and western clades of the Texas

425 horned lizard. We do not know, however, whether the offspring from these pairings experience

426 lower fitness in the wild. If there is a reduction in fitness, this could support full species

427 delimitation for these clades and warrants further investigation. Interestingly, it appears that most

428 gene flow between the eastern and western clades has been male-mediated. Of the 38 individuals

429 that had evidence of admixture between the two clades, 95\% (36 of 38) had a nuclear signature 
430 of the west cluster and an eastern mitochondrial haplotype. There were only two individuals with

431 north nuclear ancestry and western clade mitochondrial haplotypes located in Brewster Co.

432 Whether this pattern is related to hybrid incompatibilities (i.e. Haldane's rule; Haldane, 1922) is

433 unknown and requires further study.

434 The microsatellite data detect the western mitochondrial clade and also split individuals

435 in the eastern mitochondrial clade into north and south populations. The most likely dispersal

436 barrier between the south and north populations is the Balcones Escarpment (Fig. 1). The

437 Balcones Escarpment extends through central Texas, from the southwest to the northeast, and is

438 a series of cliffs, hills, and plateaus reaching up to about $300 \mathrm{~m}$ in height (Abbott \& Woodruff

439 Jr., 1986). This geologic feature separates the more xeric habitat of the Edwards Plateau from the

440 more mesic lowlands of the South Texas Plains and East-Central Texas Plains. Individuals to the

441 north of this feature have high ancestry in the north population, whereas individuals south of the

442 escarpment have predominantly south ancestry. Furthermore, only four of 74 control region

443 haplotypes found in these two populations are shared across this potential barrier. A number of

444 reptiles and amphibians in Texas have their eastern and western range boundaries along this

445 escarpment (Smith \& Buechner, 1947). For example, of the 23 species of lizards that have ranges

446 reaching the Balcones Escarpment, only two species are found on both sides of the barrier: $P$.

447 cornutum, the focus of this study, and Sceloporus olivaceus. Phylogeographic studies on snakes,

448 lizards, salamanders, and rodents have also found evidence for genetic breaks across this

449 potential barrier (Chippindale et al., 2000; Castoe, Spencer \& Parkinson, 2007; Neiswenter \&

450 Riddle, 2010; Anderson \& Light, 2012; Moseley et al., 2015; Cox et al., 2018). Our genetic data

451 suggest that this barrier may also limit dispersal for Texas horned lizards, but perhaps not to the

452 degree that has been detected in some of these other studies. 
454 also be considered separate management units (MUs; Moritz, 1994), based on their differentiation at microsatellite loci and limited overlap in mtDNA haplotypes indicating

456 dispersal constraints between these clusters. These two populations are also found in different 457 habitats.

Dispersal distances (i.e. from nest to area of first breeding) are currently unknown for 459 Texas horned lizards, but radio-telemetry studies, anatomy, and life history characteristics 460 indicate that the species is generally sedentary and probably has limited long-distance dispersal 461 capabilities. Typical home ranges are 0.4-7.0 ha for adult horned lizards and daily movement distances are 0-247 $\mathrm{m}$, although distances up to $\sim 800 \mathrm{~m}$ over several days of travel have been 463 detected in a few cases (Fair \& Henke, 1999; Burrow et al., 2001; Stark, Fox \& Leslie, 2005; 464 Endriss, 2006; Wall, 2014; Mitchell, 2017). Horned lizards have a flat, tank-like body form that 465 makes them fairly slow and easy to capture once detected. As a result of this body form, Texas 466 horned lizards rely mainly on crypsis and remaining immobile for long periods of time to avoid 467 detection by predators (Sherbrook, 2003). The presence of an isolation-by-distance pattern in the 468 microsatellite data across all sampling sites, as well as for sites within the northern population, is 469 also consistent with limited dispersal (this study). Population structure as measured by $\phi_{\mathrm{PT}}$ was 470 higher for the mitochondrial locus than for nuclear microsatellites. Stronger population structure 471 at mtDNA compared to nuclear loci may also be an indication that populations have recently 472 become fragmented and isolated. Mitochondrial loci might be expected to reveal the effects of 473 drift first since they have a lower effective population size than nuclear loci. The relatively low 474 mtDNA haplotype diversity seen at some sampling sites (Table 3) may be indicative of isolation 475 of those sites. 
477 symbolic status in historical accounts and folklore (Welch, 1993; Manaster, 1997; Sherbrooke,

478 2003). Anecdotal accounts suggest that these lizards have been moved extensively by people,

479 and as a result, this species has become locally established outside its native range in coastal

480 areas in the south-eastern United States (Price, 1990). For example, a single pet store in the

481 1950s reported exporting as many as 50,000 Texas horned lizards per year to various areas in the

482 U.S. (Dropkin, 2015). Texas horned lizards were also given out for free at some gas stations in

483 Texas with the purchase of a full tank of gas, and they were traded extensively among boys at 484 Boy Scout Jamborees (Welch, 1993; Manaster, 1997; Dropkin, 2015). Even today, the authors of

this study have on multiple occasions been told by well-intentioned horned lizard enthusiasts that they have intentionally translocated horned lizards many kilometers to put them on their property or on the property of a friend or relative, or that they simply let them loose, far from where they had been found, after trying to keep the lizards as pets.

The widely separated and isolated occurrences of some admixed individuals is consistent with human-mediated movement from anecdotal accounts. If the admixture we observed was due simply to natural dispersal, we would have expected to find admixture primarily in regions where the microsatellite clusters come into contact. For instance, the west and north populations come into contact in the Chihuahua desert ecoregion in Brewster County, TX where we found evidence for admixture from the microsatellite and mitochondrial loci. We were not able to determine if there was evidence for admixture along the Balcones Escarpment where the north and south populations might be expected to come into contact, as this species has been extirpated from most of the eastern and southern border of the escarpment and only a few horned lizards were sampled directly north of the escarpment in the Edwards Plateau. The presence of some 
499 west ancestry in widely separated individuals within the geographic range of the north and south

500 microsatellite populations, as well as the presence of south ancestry in northern Texas (e.g. at the

501 Matador WMA) or north ancestry in southern Texas (e.g. at the Chaparral WMA) seems to be at

502 odds with natural dispersal patterns.

\section{Conclusions}

504 Reintroductions of the Texas horned lizard are only planned for areas that historically had 505 horned lizards, currently have suitable habitat, and are within the geographic ranges

506 encompassed by the north and south populations. We recommend that breeding facilities at

507 Texas zoos keep individuals from the three microsatellite genetic clusters separate and return

508 their offspring to regions that correspond to their microsatellite genetic cluster. This strategy is

509 based on the indication that these lizards may be regionally-adapted. Assuming reintroductions

510 are successful, there may also be nearby populations that will eventually come into contact with

511 these introduced individuals. Avoiding the mixing of differentiated clusters would therefore be

512 advisable to reduce the chances of outbreeding depression. Nonetheless, recent reviews have

513 suggested that fears of outbreeding depression may have been over-emphasized in some

514 conservation programs (Frankham et al., 2011; Frankham et al., 2017; Ralls et al., 2018). This

515 may be especially true for instances of genetic rescue in which small populations are

516 experiencing inbreeding depression and need to be augmented to increase genetic diversity

517 (Frankham, 2015; 2016; Ralls et al., 2018). For Texas horned lizards, there is the luxury of

518 taking a more cautionary approach, since this species is still abundant with high genetic variation

519 in many areas within each of our defined genetic clusters. The presence of the west-east

520 mitochondrial divide and the fact that microsatellite clusters cover distinct ecoregions further

521 supports that this more cautionary approach is warranted for this species (Frankham et al., 2011). 
523 between these populations given our evidence of admixture in unexpected areas. Selection is

524 expected to eventually remove the deleterious effects of outbreeding depression (Edmands et al.,

525 2005; Erickson \& Fenster, 2006), and it is therefore possible that the admixed individuals we

526 found were a product of that selection. We still do not know, however, if there are fitness costs

527 associated with admixture (especially for the western and eastern clades) or if there are fitness

528 costs to moving these lizards into habitats that are distinctly different from their ancestral areas.

529 If present, either one or both of these fitness costs would decrease the effectiveness of

530 reintroduction efforts. In the future, we recommend that studies be conducted to determine if

531 there is evidence for regional adaptations that correspond to the genetic clusters uncovered in this

532 study. Of course, there may be even more fine-scaled, locally adapted units due to the presence

533 of multiple ecoregions within these clusters. In addition to the behavioral and morphological

534 studies suggested earlier, NGS (next generation sequencing) methods could also be used to

535 identify loci which may be under differential selection to better delineate adaptive conservation

536 units in this species (e.g. Funk et al., 2012).

537

\section{Acknowledgements}

539 We thank the large number of volunteers from Texas Parks and Wildlife, Texas Master

540 Naturalists, Horned Lizard Conservation Society, Fort Worth Zoo, Dallas Zoo, San Antonio Zoo,

541 and others that helped us obtain samples. Lee Ann Linam was especially instrumental in

542 organizing the collection effort and helping collect samples. Jeff Bonner, Jason Brewer, Ruston

543 Hartdegen, Ashley Inslee, Kris Karsten, Richard Kazmaier, Bradley Lawrence, Kathy and John

544 Lupardus, Chad Montgomery, Maureen Morris, Wanda Olszewski, R.L. Orth, Richard Reams, 
545 Chip Ruthven, Don Sias, and Sara Weaver provided large numbers of samples from specific

546 localities for this study. Cory Leach, Emmanuela Mujica, and Megan Raetz helped develop

547 genetic markers and process samples in the laboratory.

548

\section{References}

550 Abbott, P.L. and Woodruff Jr., C.M. (1986) The Balcones Escarpment: Geology, Hydrology,

551 Ecology and Social Development in Central Texas. Geological Society of America, San Antonio,

552 Texas

553 Andersen JJ, Light JE (2012) Phylogeography and subspecies revision of the hispid pocket

554 mouse, Chaetodipus hispidus (Rodentia: Heteromyidae). J Mammal 93:1195-1215

555 Arèvalo E, Davis S, Sites J (1994) Mitochondrial DNA sequence divergence and phylogenetic

556 relationships among 8 chromosome races of the Sceloporus grammicus complex

557 (Phrynosomatidae) in Central Mexico. Systematic Biol 43:387-418

558 Attard CRM, Moller LM, Sasaki M, Hammer MP, Bice CM, Brauer CJ, Carvalho DC, Harris

559 JO, Beheregaray LB (2016) A novel holistic framework for genetic-based captive-breeding and

560 reintroduction programs. Conserv Biol 30:1060-1069

561 Axtell RW (1977) Ancient playas and their influence on the recent herpetofauna of the northern

562 Chihuahuan Desert. Transactions of the Symposium on the Biological Resources of the

563 Chihuahuan Desert Region, United States and Mexico 3:493-512

564 Ballinger RE (1974) Reproduction of the Texas horned lizard Phrynosoma cornutum.

565 Herpetologica 30:321-327

566 Barilani M, Deregnaucourt S, Gallego S, Galli L, Mucci N, Piombo R, Puigcerver M, Rimondi

567 S, Rodríguez-Teijeiro JD, Spanò S, Randi E (2005) Detecting hybridization in wild (Coturnix c.

568 coturnix) and domesticated (Coturnix c. japonica) quail populations. Biol Conserv 126:445-455

569 Blair C, Bryson RW (2017) Cryptic diversity and discordance in single-locus species

570 delimitation methods within horned lizards (Phrynosomatidae: Phrynosoma). Mol Ecol Resour

571 17:1168-1182

572 Bohling JH, Adams JR, Waits LP (2013) Evaluating the ability of Bayesian clustering methods

573 to detect hybridization and introgression using an empirical red wolf data set. Mol Ecol 22:74-86

574 Brookfield JFY (1996) A simple new method for estimating null allele frequency from

575 heterozygote deficiency. Molecular Ecology 5:453-455

576 Burrow AL, Kazmaier RT, Hellgren EC, Ruthven DC (2001) Microhabitat selection by Texas

577 horned lizards in southern Texas. J Wildlife Manage 65:645-652 
578 Carlson SM, Cunningham CJ, Westley PAH (2014) Evolutionary rescue in a changing world.

579 Trends Ecol Evol 29:521-530

580 Carlsson J (2008) Effects of microsatellite null alleles on assignment testing. J Heredity 99:616581623

582 Castoe TA, Spencer CL, Parkinson CL (2007) Phylogeographic structure and historical

583 demography of the western diamondback rattlesnake (Crotalus atrox): A perspective on North

584 American desert biogeography. Mol Phylogenet Evol 42:193-212

585 Chapuis M, Estoup A (2007) Microsatellite null alleles and estimation of population

586 differentiation. Mol Biol Evol 24:621-631

587 Chippindale PT, Price AH, Wiens JJ, Hillis DM (2000) Phylogenetic relationships and

588 systematic revision of central Texas hemidactyliine plethodontid salamanders. Herpetol Mono $589 \quad 14: 1-80$

590 Cox CL, Rabosky ARD, Holmes IA, Reyes-Velasco J, Roelke CE, Smith EN, Flores-Villela O, 591 McGuire JA, Campbell JA (2018) Synopsis and taxonomic revision of three genera in the snake 592 tribe Sonorini. J Nat Hist 52:945-988

593 Crandall KA, Bininda-Emonds ORP, Mace GM, Wayne RK (2000) Considering evolutionary 594 processes in conservation biology. Trends Ecol Evol 15:290-295

595 Donaldson W, Price A, Morse J (1994) The current status and future prospects of the Texas 596 horned lizard (Phrynosoma cornutum) in Texas. Tex J Sci 46:97-113

597 Dropkin A (2015) Our Toad to Ruin. Texas Monthly. https://www.texasmonthly.com/the598 culture/our-toad-to-ruin/ Accessed Oct 30, 2018

599 Ebenhard T (1995) Conservation breeding as a tool for saving animal species from extinction. 600 Trends Ecol Evol 10:438-443

601 Edmands S, Feaman HV, Harrison JS, Timmerman CC (2005) Genetic consequences of many 602 generations of hybridization between divergent copepod populations. J Hered 96:114-123

603 Endriss DA (2006) Ecology of an urban population of the Texas horned lizard (Phrynosoma 604 cornutum) in Central Oklahoma. Masters Thesis, Oklahoma State University

605 Erickson DL, Fenster CB (2006) Intraspecific hybridization and the recovery of fitness in the 606 native legume Chamaecrista fasciculata. Evolution 60:225-233

607 Evanno G, Regnaut S, Goudet J (2005) Detecting the number of clusters of individuals using the 608 software STRUCTURE: a simulation study. Mol Ecol 14:2611-2620

609 Excoffier L, Lischer HEL (2010) Arlequin suite ver 3.5: a new series of programs to perform 610 population genetics analyses under Linux and Windows. Mol Ecol Resour 10:564-567

611 Fair WS, Henke SE (1999) Movements, home ranges, and survival of Texas horned lizards 612 (Phrynosoma cornutum). J Herpetol 33:517-525 
613 Frankham R (2015) Genetic rescue of small inbred populations: meta-analysis reveals large and 614 consistent benefits of gene flow. Mol Ecol 24:2610-2618

615 Frankham R (2016) Genetic rescue benefits persist to at least the F3 generation, based on a meta616 analysis. Biol Conserv 195:33-36

617 Frankham R, Ballou JD, Briscoe DA (2010) Introduction to conservation genetics. Cambridge 618 University Press, New York

619 Frankham R, Ballou JD, Eldridge MDB, Lacy RC, Ralls K, Dudash MR, Fenster CB (2011)

620 Predicting the probability of outbreeding depression. Conserv Biol 25:465-475

621 Frankham R, Ballou JD, Ralls K, Eldridge MDB, Dudash MR, Fenster CB, Lacy RC, Sunnucks 622 P (2017) Genetic Management of Fragmented Animal and Plant Populations. Oxford University 623 Press, Oxford, UK

624 Fu YX (1997) Statistical tests of neutrality of mutations against population growth, hitchhiking 625 and background selection. Genetics 147:915-925

626 Funk WC, Mckay JK, Hohenlohe PA, Allendorf FW (2012) Harnessing genomics for delineating 627 conservation units. Trends Ecol Evol 27:489-496

628 Griffith G, Bryce S, Omernik J, Rogers A (2007) Ecoregions of Texas. Texas Commission on 629 Environmental Quality, Austin, TX

630 Guerra TM (1998) Genetic analysis of the Texas horned lizard (Phrynosoma cornutum):

631 implications for conservation. Masters Thesis, Texas A\&M University

632 Haldane, JBS (1922) Sex-ratio and unisexual sterility in hybrid animals. Journal of Genetics

633 12:101-109

634 Hammerson GA (2007) Phrynosoma cornutum. The IUCN Red List of Threatened Species. In: 635 https://www.iucnredlist.org/en. Accessed Oct 30, 2018

636 Henke SE (2003) Baseline survey of Texas horned lizards, Phrynosoma cornutum, in Texas. 637 Southwest Nat 48:278-282

638 Houde ALS, Garner SR, Neff BD (2015) Restoring species through reintroductions: strategies 639 for source population selection. Restor Ecol 23:746-753

640 Huelsenbeck JP, Ronquist F (2001) MRBAYES: Bayesian inference of phylogenetic trees. 641 Bioinformatics 17:754-755

642 IUCN/SSC (2013) Guidelines for Reintroductions and Other Conservation Translocations.

643 Version 1.0. IUCN:57. https://portals.iucn.org/library/efiles/documents/2013-009.pdf Accessed 644 Oct 30,2018

645 Jakobsson M, Rosenberg NA (2007) CLUMPP: a cluster matching and permutation program for 646 dealing with label switching and multimodality in analysis of population structure.

647 Bioinformatics 23:1801-1806 
648 Jamieson IG (2015) Significance of population genetics for managing small natural and 649 reintroduced populations in New Zealand. New Zealand J Ecol 39:1-18

650 Johnson BB, White TA, Phillips CA, Zamudio KR (2015) Asymmetric introgression in a spotted 651 salamander hybrid zone. J Hered 106:608-617

652 Johnson WE, Onorato DP, Roelke ME, Land ED, Cunningham M, Belden RC, McBride R, 653 Jansen D, Lotz M, Shindle D, Howard J, Wildt DE, Penfold LM, Hostetler JA, Oli MK, O'Brien 654 SJ (2010) Genetic restoration of the Florida panther. Science 329:1641-1645

655 Kalinowski ST (2005) HP-RARE 1.0: a computer program for performing rarefaction on 656 measures of allelic richness. Mol Ecol Notes 5:187-189

657 Kumar S, Stecher G, Li M, Knyaz C, Tamura K (2018) MEGA X: Molecular evolutionary 658 genetics analysis across computing platforms. Mol Biol Evol 35:1547-1549

659 Lenormand T (2002) Gene flow and the limits to natural selection. Trends Ecol Evol 17:183-189

660 Macey JR, Wang YZ, Ananjeva NB, Larson A, Papenfuss TJ (1999) Vicariant patterns of 661 fragmentation among gekkonid lizards of the genus Teratoscincus produced by the Indian 662 collision: A molecular phylogenetic perspective and an area cladogram for Central Asia. Mol 663 Phylogenet Evol 12:320-332

664 Manaster J (1997) Horned Lizards. University of Texas Press, Austin, Texas

665 Marr MM, Brace S, Schreve DC, Barnes I (2018) Identifying source populations for the 666 reintroduction of the Eurasian beaver, Castor fiber L. 1758, into Britain: evidence from ancient 667 DNA. Sci Rep UK 8:2708

668 Marsh DM, Page RB, Hanlon TJ, Corritone R, Little EC, Seifert DE, Cabe PR (2008) Effects of 669 roads on patterns of genetic differentiation in red-backed salamanders, Plethodon cinereus. 670 Conserv Genet 9:603-613

671 Maxwell S, Fuller RA, Brooks TM, Watson JEM (2016) The ravages of guns, nets and 672 bulldozers. Nature 536:143-145

673 Meirmans PG, Hedrick PW (2011) Assessing population structure: F-ST and related measures. 674 Mol Ecol Resour 11:5-18

675 Mitchell KJ (2017) Spatial use and survivorship of translocated wild-caught Texas horned lizards 676 (Phrynosoma cornutum). Masters Thesis, Tarleton State University

677 Moritz C (1994) Defining evolutionarily significant units for conservation. Trends Ecol Evol 678 9:373-375

679 Moseley MA, Cox CL, Streicher JW, Roelke CE, Chippindale PT (2015) Phylogeography and 680 lineage-specific patterns of genetic diversity and molecular evolution in a group of North 681 American skinks. Biol J Linn Soc 116:819-833

682 Neiswenter SA, Riddle BR (2010) Diversification of the Perognathus flavus species group in 683 emerging arid grasslands of western North America. J Mammal 91:348-362 
684 Omernick JM (1987) Ecoregions of the conterminous United States. Map (scale 1:7,500,000).

685 Ann Am Assoc Geogr 77:118-125

686 Omernick JM (1995) Ecoregions: A spatial framework for environmental management. In:

687 Davis, W.S., Simon, T.P. (ed) Biological Assessment and Criteria: Tools for Water Resource

688 Planning and Decision Making. Lewis Publishers, Boca Raton, FL, pp 49-62

689 Omernik, J.M., Griffith, G.E. (2014) Ecoregions of the conterminous United States: evolution of 690 a hierarchical spatial framework. Environ Manage 54:1249-1266

691 Peakall R, Smouse PE (2006) GENALEX 6: genetic analysis in Excel. Population genetic 692 software for teaching and research. Mol Ecol Notes 6:288-295

693 Peakall R, Smouse PE (2012) GenAlEx 6.5: genetic analysis in Excel. Population genetic 694 software for teaching and research-an update. Bioinformatics 28:2537-2539

695 Petit RJ, El Mousadik A, Pons O (1998) Identifying populations for conservation on the basis of 696 genetic markers. Conserv Biol 12:844-855

697 Price AH (1990) Phrynosoma cornutum (Harlan): Texas horned lizard. Catalogue of American 698 Amphibians and Reptiles 469:1-7

699 Pritchard JK, Stephens M, Donnelly P (2000) Inference of population structure using multilocus 700 genotype data. Genetics 155:945-959

701 Puechmaille SJ (2016) The program structure does not reliably recover the correct population 702 structure when sampling is uneven: subsampling and new estimators alleviate the problem. Mol 703 Ecol Resour 16:608-627

704 Ralls K, Ballou JD, Dudash MR, Eldridge MDB, Fenster CB, Lacy RC, Sunnucks P, Frankham

$705 \mathrm{R}$ (2018) Call for a paradigm shift in the genetic management of fragmented populations.

706 Conserv Lett 11:UNSP e12412

707 Reeves C (1969) Pluvial Lake Palomas northwestern Chihuahua, Mexico. In: Cordoba, D.A., 708 Wengerd, S.A., Shomaker, J.W. (ed) Guidebook 20: The Border Region (Chihuahua, Mexico, \& 709 USA). New Mexico Geological Society, Socorro, NM, pp 143-154

710 Reeves C (1965) Pluvial Lake Palomas, northwestern Chihuahua, Mexico and Pleistocene 711 geologic history of south-central New Mexico. In: Fitzimmons, J.P. and Balk, C.L. (ed)

712 Guidebook 16: Southwestern New Mexico II. New Mexico Geological Society, Socorro, NM, pp 713 199-203

714 Rogers A (1995) Genetic evidence for a Pleistocene population explosion. Evol 49:608-615

715 Ronquist F, Teslenko M, van der Mark P, Ayres DL, Darling A, Hohna S, Larget B, Liu L, 716 Suchard MA, Huelsenbeck JP (2012) MrBayes 3.2: Efficient Bayesian phylogenetic inference 717 and model choice across a large model space. Systematic Biol 61:539-542

718 Rosenthal, J., Forstner, M.R.J. (2014) Effects of Plio-Pleistocene barrier on Chihuahuan Desert 719 herpetofauna. Proceedings of the Sixth Symposium on the Natural Resources of the Chihuahuan 720 Desert Region:269-282 
721 Rousset F (2008) GENEPOP ' 007: a complete re-implementation of the GENEPOP software for

722 Windows and Linux. Mol Ecol Resour 8:103-106

723 Rozas J, Ferrer-Mata A, Carlos Sanchez-DelBarrio J, Guirao-Rico S, Librado P, Ramos-Onsins

724 SE, Sanchez-Gracia A (2017) DnaSP 6: DNA Sequence polymorphism analysis of large data

725 sets. Mol Biol Evol 34:3299-3302

726 Schenekar T, Weiss S (2011) High rate of calculation errors in mismatch distribution analysis

727 results in numerous false inferences of biological importance. Heredity 107:511-512

728 Schwartz TS, Beheregaray LB (2008) Using genotype simulations and Bayesian analyses to

729 identify individuals of hybrid origin in Australian bass: lessons for fisheries management. J Fish

730 Biol 72:435-450

731 Seddon PJ (2010) From reintroduction to assisted colonization: moving along the conservation

732 translocation spectrum. Restor Ecol 18:796-802

733 Sherbrooke WC (2003) Introduction to Horned Lizards of North America. University of

734 California Press, Berkeley

735 Smith HM, Buechner HK (1947) The influence of the Balcones Escarpment on the distribution

736 of amphibians and reptiles in Texas. Bulletin of the Chicago Academy of Sciences 8:1-16

737 Stark RC, Fox SF, Leslie DM (2005) Male Texas horned lizards increase daily movements and

738 area covered in spring: A mate searching strategy?. J Herpetol 39:169-173

739 Strain WS (1966) Biancan mammalian fauna and Pleistocene formations, Hudspeth County,

740 Texas. Bulletin of the Texas Memorial Museum 10:1-155

741 Tajima F (1989) Statistical method for testing the neutral mutation hypothesis by DNA

742 polymorphism. Genetics 123:585-595

743 Thompson JD, Higgins DG, Gibson TJ (1994) CLUSTAL W: improving the sensitivity of

744 progressive multiple sequence alignment through sequence weighting, position-specific gap

745 penalties and weight matrix choice. Nucleic Acid Res 22:4673-4680

746 Vähä J-P, Primmer CR (2006) Efficiency of model-based Bayesian methods for detecting hybrid

747 individuals under different hybridization scenarios and with different numbers of loci. Mol. Ecol.

$748 \quad 15: 63-72$

749 Van Oosterhout C, Hutchinson WF, Wills DPM, Shipley P (2004) MICRO-CHECKER: software

750 for identifying and correcting genotyping errors in microsatellite data. Mol Ecol Notes 4:535-538

751 Wall AE (2014) Home range and genetics of Texas horned lizards (Phrynosoma cornutum) in

752 two small Texas towns in South Texas. Masters Thesis, Texas Christian University

753 Wang J (2017) The computer program STRUCTURE for assigning individuals to populations:

754 easy to use but easier to misuse. Mol Ecol Resour 17:981-990

755 Weeks AR, Sgro CM, Young AG, Frankham R, Mitchell NJ, Miller KA, Byrne M, Coates DJ, 756 Eldridge MDB, Sunnucks P, Breed MF, James EA, Hoffmann AA (2011) Assessing the benefits 
757 and risks of translocations in changing environments: a genetic perspective. Evol Appl 4:709-

$758 \quad 725$

759 Welch JR (1993) Ye Legendary Texas Horned Frog. Yellow Rose Press, Irving, Texas

760 Williams DA, Leach C, Hale AM, Karsten KB, Mujica E, Barber D, Linam LA, Rains N (2012)

761 Development of tetranucleotide microsatellite loci and a non-invasive DNA sampling method for

762 Texas horned lizards (Phrynosoma cornutum). Conserv Genet Resour 4:43-45

763 Williams DA, Osentoski MF (2007) Genetic considerations for the captive breeding of tortoises

764 and freshwater turtles. Chelonian Conserv Biol 6:302-313 


\section{Table $\mathbf{1}$ (on next page)}

Mean \pm SE genetic diversity measures at ten microsatellite loci for 449 Texas horned lizards, Phrynosoma cornutum, from 16 sampling sites (each with $\geq 10$ individuals).

Site column is the number corresponding to map locations; cluster column is the population determined by STRUCTURE to which each site belongs: $\mathrm{W}$ - west, $\mathrm{N}$ - north, $\mathrm{S}$ - south; $\mathrm{N}$ is the number of individuals sampled at each site; $N_{A}$ is the number of alleles; $A_{R}$ is allelic richness standardized for 10 individuals; $H_{O}$ is observed heterozygosity; $H_{E}$ is expected heterozygosity; and $\mathrm{F}_{\mathrm{IS}}$ is the inbreeding coefficient. For sampling site names, $\mathrm{SP}=$ state park, WMA = wildlife management area, $\mathrm{CMA}=$ Cross Bar Management Area, Co. = county RRQRR = Rolling Plains Quail Research Ranch. 


\begin{tabular}{|c|c|c|c|c|c|c|c|c|c|}
\hline State & Site & Sampling Site Name & Cluster & $\mathrm{N}$ & $\mathrm{N}_{\mathrm{A}}$ & $A_{R}$ & $\mathrm{H}_{\mathrm{O}}$ & $\mathrm{H}_{\mathrm{E}}$ & $\mathrm{F}_{\text {IS }}$ \\
\hline \multirow[t]{14}{*}{ Texas } & 1 & Brewster Co. & $\mathrm{W} / \mathrm{N}$ & 31 & $13.00 \pm 1.50$ & $8.73 \pm 0.67$ & $0.79 \pm 0.04$ & $0.83 \pm 0.03$ & $0.05 \pm 0.04$ \\
\hline & 2 & Hueco Tanks SP & W & 12 & $8.20 \pm 0.84$ & $7.64 \pm 0.77$ & $0.79 \pm 0.05$ & $0.78 \pm 0.04$ & $-0.02 \pm 0.03$ \\
\hline & 3 & Seminole Canyon SP & $\mathrm{N}$ & 17 & $11.10 \pm 0.82$ & $9.16 \pm 0.62$ & $0.86 \pm 0.03$ & $0.84 \pm 0.03$ & $-0.03 \pm 0.03$ \\
\hline & 4 & Midland Co. & $\mathrm{N}$ & 30 & $13.20 \pm 1.86$ & $8.80 \pm 0.75$ & $0.83 \pm 0.03$ & $0.84 \pm 0.03$ & $0.02 \pm 0.01$ \\
\hline & 5 & Camp Bowie & $\mathrm{N}$ & 11 & $8.00 \pm 0.56$ & $7.75 \pm 0.52$ & $0.86 \pm 0.04$ & $0.81 \pm 0.02$ & $-0.05 \pm 0.04$ \\
\hline & 6 & Mitchell Co. & $\mathrm{N}$ & 14 & $9.40 \pm 1.28$ & $8.16 \pm 0.93$ & $0.83 \pm 0.03$ & $0.83 \pm 0.02$ & $-0.01 \pm 0.03$ \\
\hline & 7 & Grey Co. & $\mathrm{N}$ & 11 & $9.40 \pm 0.95$ & $9.08 \pm 0.86$ & $0.86 \pm 0.05$ & $0.86 \pm 0.03$ & $-0.04 \pm 0.05$ \\
\hline & 8 & Yoakum Dunes WMA & $\mathrm{N}$ & 36 & $12.70 \pm 1.62$ & $8.56 \pm 0.72$ & $0.84 \pm 0.04$ & $0.83 \pm 0.04$ & $-0.01 \pm 0.01$ \\
\hline & 9 & Matador WMA & $\mathrm{N}$ & 55 & $14.50 \pm 2.10$ & $8.62 \pm 0.66$ & $0.86 \pm 0.02$ & $0.85 \pm 0.02$ & $-0.01 \pm 0.01$ \\
\hline & 10 & RPQRR & $\mathrm{N}$ & 79 & $15.50 \pm 2.20$ & $8.60 \pm 0.73$ & $0.86 \pm 0.02$ & $0.84 \pm 0.03$ & $-0.02 \pm 0.02$ \\
\hline & 11 & CMA & $\mathrm{N}$ & 20 & $11.30 \pm 1.33$ & $8.49 \pm 0.77$ & $0.82 \pm 0.06$ & $0.81 \pm 0.05$ & $-0.01 \pm 0.04$ \\
\hline & 12 & Chaparral WMA & $\mathrm{S}$ & 63 & $14.50 \pm 1.52$ & $8.68 \pm 0.56$ & $0.83 \pm 0.02$ & $0.87 \pm 0.01$ & $0.04 \pm 0.02$ \\
\hline & 13 & Starr Co. & $\mathrm{S}$ & 10 & $8.10 \pm 0.69$ & $8.10 \pm 0.69$ & $0.82 \pm 0.03$ & $0.81 \pm 0.02$ & $-0.02 \pm 0.04$ \\
\hline & 14 & Matagorda Island WMA & $\mathrm{S}$ & 30 & $8.90 \pm 1.15$ & $6.63 \pm 0.58$ & $0.70 \pm 0.05$ & $0.79 \pm 0.02$ & $0.11 \pm 0.05$ \\
\hline Colorado & 15 & Colorado & $\mathrm{N}$ & 13 & $10.40 \pm 0.85$ & $9.63 \pm 0.73$ & $0.87 \pm 0.03$ & $0.86 \pm 0.02$ & $-0.01 \pm 0.03$ \\
\hline New Mexico & 16 & E. New Mexico & $\mathrm{N}$ & 18 & $11.30 \pm 1.21$ & $8.90 \pm 0.86$ & $0.85 \pm 0.06$ & $0.81 \pm 0.05$ & $-0.04 \pm 0.03$ \\
\hline
\end{tabular}




\section{Table 2 (on next page)}

Average proportion of ancestry $(q)$ by ecoregion, as determined in STRUCTURE using 10 microsatellite markers for 542 Texas horned lizards, Phrynosoma cornutum.

Shading has been added to illustrate the ecoregions with the highest ancestry in each genetic cluster (West, North, South). 


\begin{tabular}{llccc}
\hline Ecoregion Level II & Ecoregion Level III & West & North & South \\
\hline South-Central Semi-Arid Prairies & High Plains & 0.01 & 0.98 & 0.01 \\
& Southwestern Tablelands & 0.02 & 0.95 & 0.03 \\
& Central Great Plains & 0.01 & 0.94 & 0.05 \\
& Edwards Plateau & 0.02 & 0.89 & 0.10 \\
& Cross Timbers & 0.01 & 0.98 & 0.01 \\
Southeastern USA Plains & East-Central Texas Plains & 0.01 & 0.06 & 0.94 \\
Tamaulipas-Texas Semiarid Plain & Southern Texas Plains & 0.01 & 0.11 & 0.88 \\
Texas-Louisiana Coastal Plain & Western Gulf Coastal Plain & 0.00 & 0.02 & 0.98 \\
Western Sierra Madre Piedmont & Madrean Archipelago & 0.98 & 0.02 & 0.00 \\
Warm Deserts & Chihuahua Deserts & 0.62 & 0.36 & 0.02 \\
\hline
\end{tabular}

1 


\section{Table 3 (on next page)}

Mitochondrial diversity at the control region for 449 Texas horned lizards, Phrynosoma cornutum, from 16 sampling sites (each with $\geq 10$ individuals).

Site column is the number corresponding to map locations; cluster column is the population determined by STRUCTURE to which each site belongs: $\mathrm{W}$ - west, $\mathrm{N}$ - north, $\mathrm{S}$ - south; $\mathrm{N}$ is number of individuals sampled at each site; $H$ is number of haplotypes; $H_{R}$ is haplotype richness standardized for 10 individuals; and $h$ is haplotype diversity. For sampling site names, $\mathrm{SP}=$ state park, WMA = wildlife management area, $\mathrm{CMA}=$ Cross Bar Management Area, Co. = county, RRQRR = Rolling Plains Quail Research Ranch. 


\begin{tabular}{lclccrcc}
\hline State & Site & Sampling site & Cluster & $\mathrm{N}$ & $\mathrm{H}$ & $\mathrm{H}_{\mathrm{R}}$ & $h$ \\
\hline Texas & 1 & Brewster Co. & $\mathrm{W} / \mathrm{N}$ & 31 & 11 & 5.26 & 0.87 \\
& 2 & Hueco Tanks SP & $\mathrm{W}$ & 12 & 2 & 1.00 & 0.49 \\
& 3 & Seminole Canyon SP & $\mathrm{N}$ & 17 & 9 & 5.58 & 0.89 \\
& 4 & Midland Co. & $\mathrm{N}$ & 30 & 4 & 1.23 & 0.25 \\
& 5 & Camp Bowie & $\mathrm{N}$ & 11 & 3 & 1.91 & 0.56 \\
& 6 & Mitchell Co. & $\mathrm{N}$ & 14 & 5 & 3.35 & 0.73 \\
& 7 & Grey Co. & $\mathrm{N}$ & 11 & 7 & 5.46 & 0.82 \\
& 8 & Yoakum Dunes WMA & $\mathrm{N}$ & 36 & 3 & 0.67 & 0.11 \\
& 9 & Matador WMA & $\mathrm{N}$ & 55 & 12 & 4.12 & 0.75 \\
& 10 & RPQRR & $\mathrm{N}$ & 79 & 7 & 2.47 & 0.47 \\
& 11 & CMA & $\mathrm{N}$ & 20 & 4 & 2.45 & 0.66 \\
& 12 & Chaparral WMA & $\mathrm{S}$ & 63 & 18 & 6.76 & 0.89 \\
& 13 & Starr Co. & $\mathrm{S}$ & 10 & 10 & 8.00 & 0.98 \\
Colorado & 14 & Matagorda Island WMA & $\mathrm{S}$ & 30 & 1 & 0.00 & 0.00 \\
New Mexico & 15 & Colorado & $\mathrm{N}$ & 13 & 3 & 2.00 & 0.73 \\
& 16 & East New Mexico & $\mathrm{N}$ & 18 & 10 & 6.47 & 0.85 \\
\hline
\end{tabular}

1 


\section{Table 4 (on next page)}

Mitochondrial diversity and demographic estimators for Texas horned lizard, Phrynosoma cornutum, western and eastern clades based on $778 \mathrm{bp}$ of the mitochondrial ND4 gene and 353 bp of the mitochondrial control region.

$\mathrm{N}$ is number of individuals; $\mathrm{H}$ is number of haplotypes; $h$ is haplotype diversity; $\pi$ is nucleotide diversity; $\theta$ is Watterson's estimator; $\tau$ is the expansion parameter. 
1

\begin{tabular}{lcccccccc}
\hline Clade & $\mathrm{N}$ & $\mathrm{H}$ & $h$ & $\pi$ & Tajima's D & Fu's Fs & $\Theta$ & $\tau$ \\
\hline ND4 Western & 16 & 10 & 0.87 & 0.0024 & $-2.044^{* *}$ & $-6.192^{* * *}$ & 3.918 & 1.895 \\
ND4 Eastern & 33 & 21 & 0.96 & 0.0059 & $-1.631^{*}$ & $-11.003 * * *$ & 8.131 & 5.852 \\
CR Western & 31 & 11 & 0.75 & 0.0051 & -1.455 & $-4.693 * *$ & 3.254 & - \\
CR Eastern & 33 & 18 & 0.92 & 0.0104 & 0.206 & $-8.541^{* * *}$ & 3.450 & - \\
\hline
\end{tabular}

* $\mathrm{P}<0.05 ; * * \mathrm{P}<0.01$; *** $\mathrm{P}<0.001$ 


\section{Figure 1}

Sampling locations of 542 Texas horned lizards, Phrynosoma cornutum, within EPA level III ecoregions

(https://www.epa.gov/eco-research/level-iii-and-iv-ecoregions-continental-united-states).

Symbols indicate assignment ( $q>0.49$ ) to different genetic clusters or populations (west, north, and south) based on multilocus microsatellite genotypes using the program STRUCTURE. 


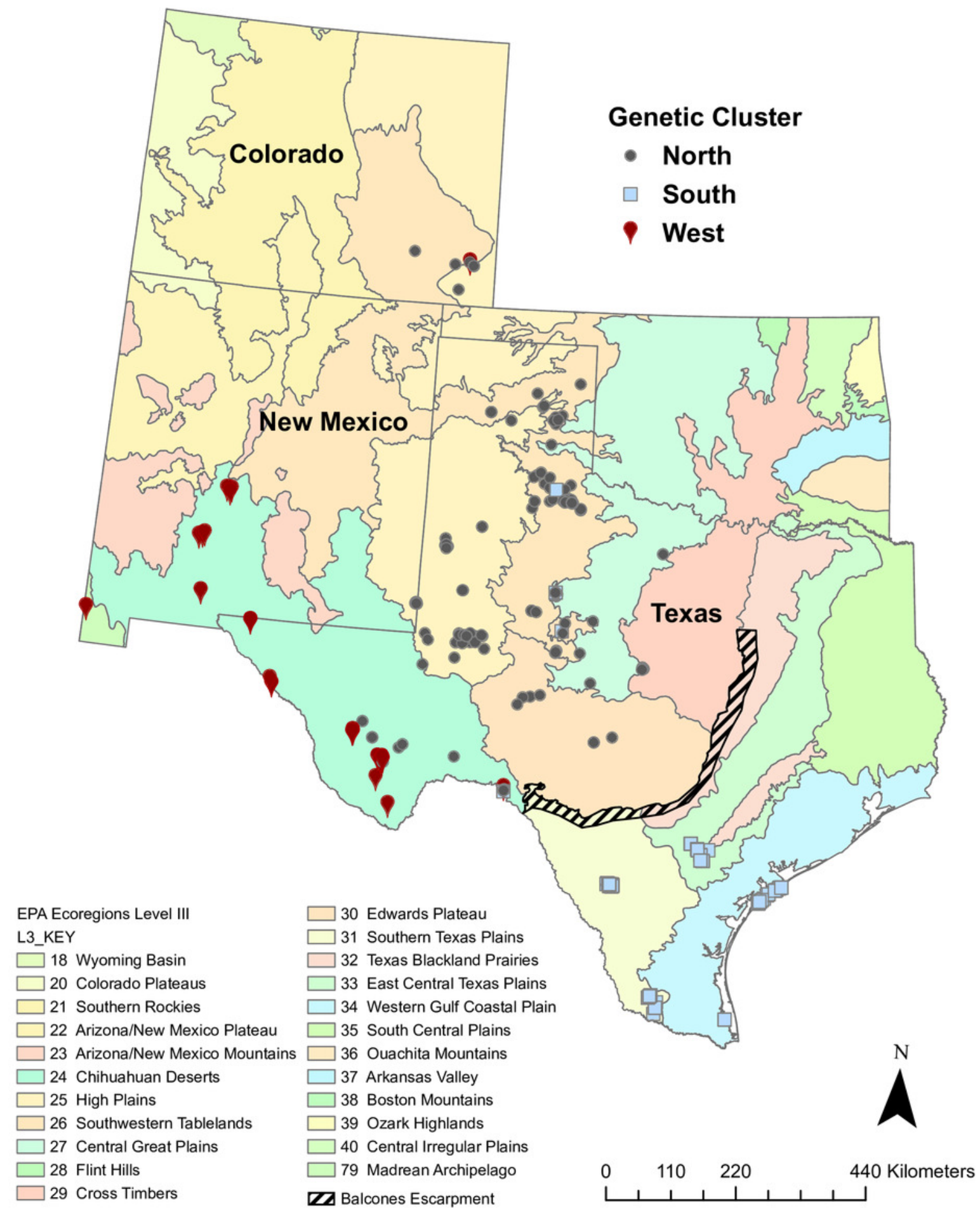


Figure 2

Locations of 16 sampling sites with $\geq 10$ individual Texas horned lizards, Phrynosoma cornutum.

Numbers are, 1 - Brewster Co., 2 - Hueco Tanks SP, 3 - Seminole Canyon SP, 4 - Midland Co., 5 - Camp Bowie, 6 - Mitchell Co., 7 - Grey Co., 8 - Yoakum Dunes WMA, 9 - Matador WMA, 10

- RPQRR, 11 - CMA, 12 - Chaparral WMA, 13 - Starr Co., 14 - Matagorda Island WMA, 15 Colorado, 16 - E. New Mexico. 


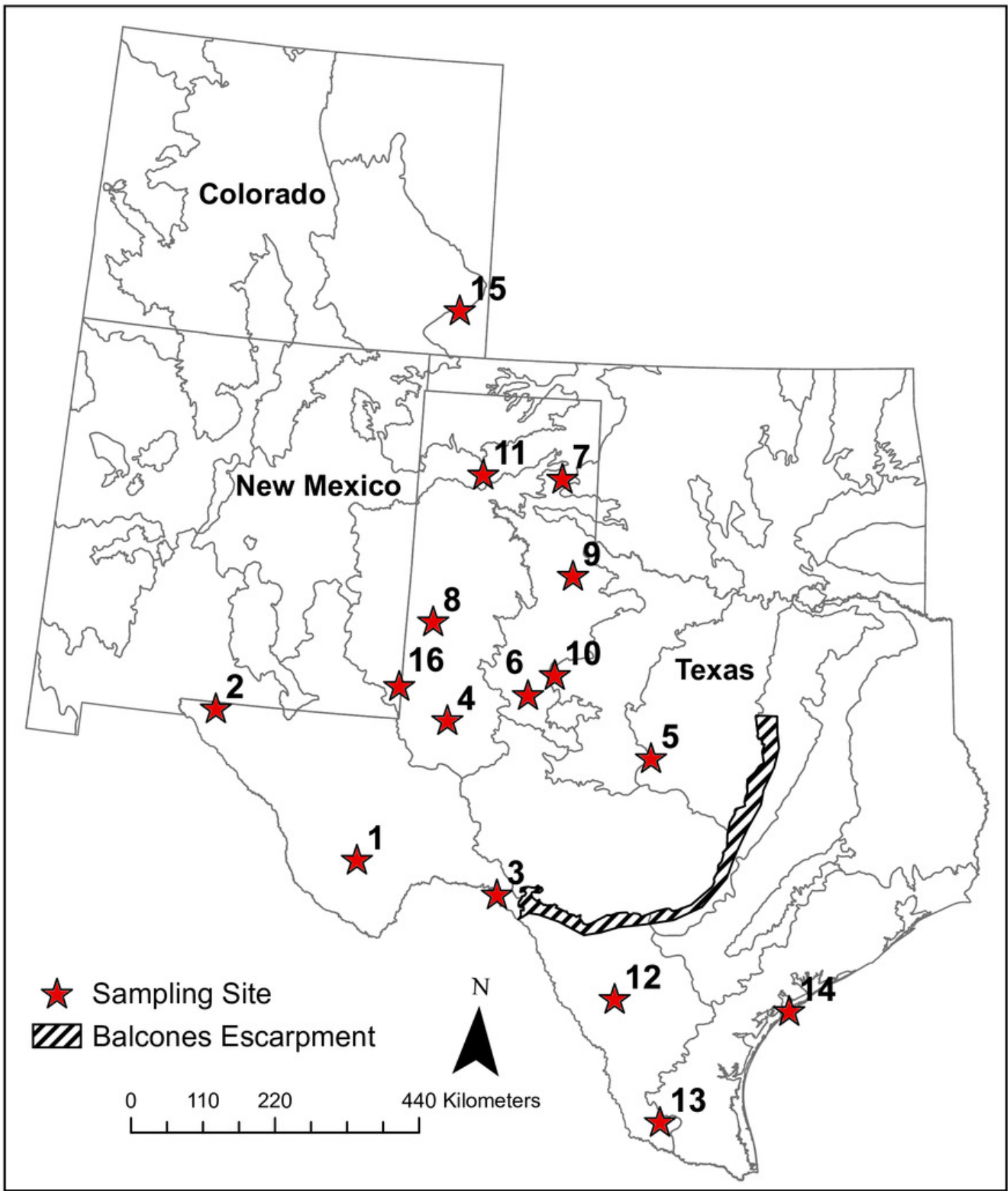


Figure 3

Principal component analysis of pairwise $\mathrm{F}^{\prime}{ }_{\text {ST }}$ values determined with ten nuclear microsatellites, between 16 sampling sites ( $n=449$ individuals) with $\geq 10$ Texas horned lizards, Phrynosoma cornutum, each.

Colors correspond to populations determined by STRUCTURE: dark red - west, light blue south, dark grey - north, dark grey and red hatch marks on \#1 indicates a mix of north and west. Numbers are sampling sites: 1 - Brewster Co., 2 - Hueco Tanks SP, 3 - Seminole Canyon SP, 4 - Midland Co., 5 - Camp Bowie, 6 - Mitchell Co., 7 - Grey Co., 8 - Yoakum Dunes WMA, 9 - Matador WMA, 10 - RPQRR, 11 - CMA, 12 - Chaparral WMA, 13 - Starr Co., 14 - Matagorda Island WMA, 15 - Colorado, 16 - E. New Mexico.

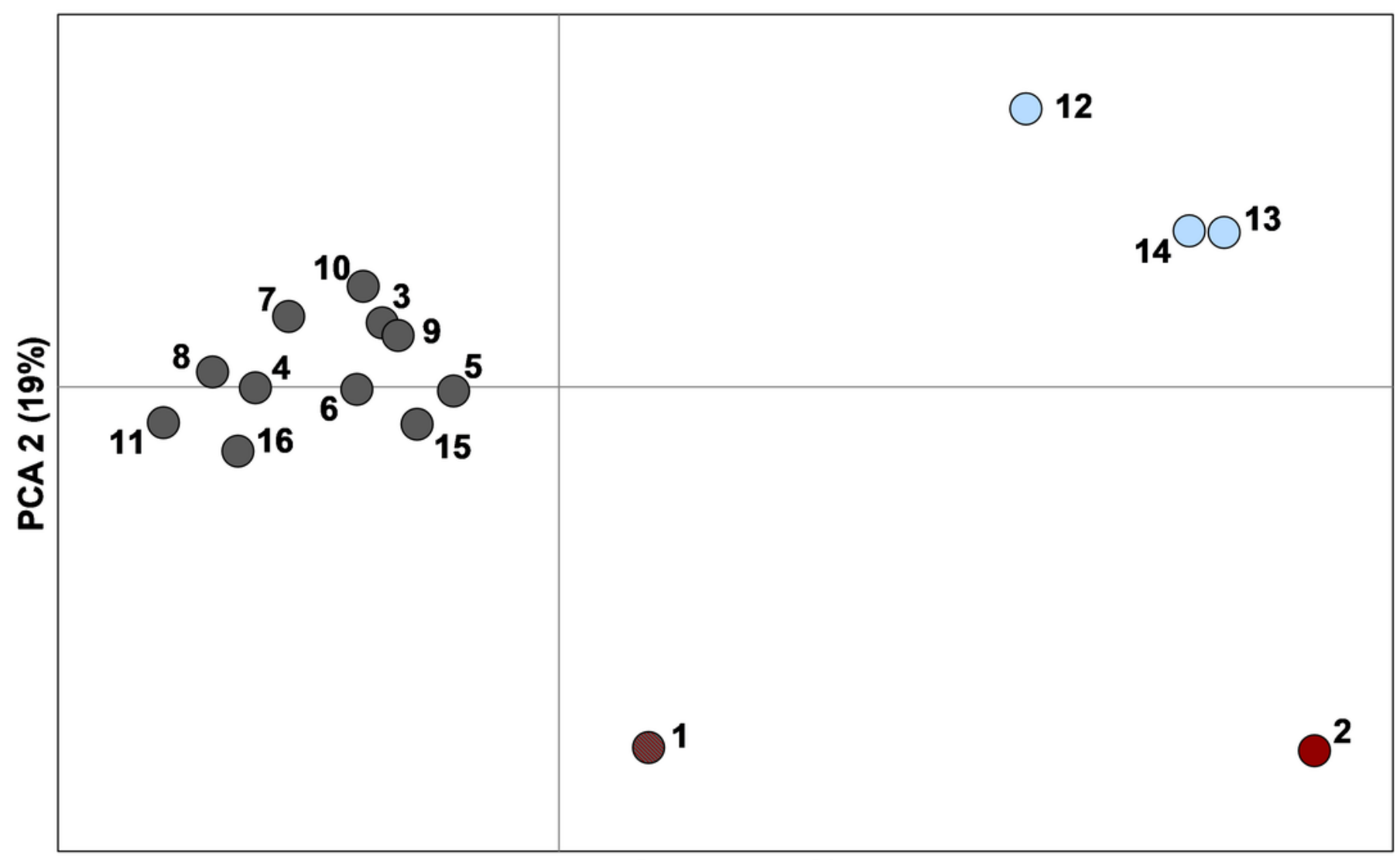

PCA 1 (33.3\%) 


\section{Figure 4}

Bayesian clustering of nuclear multilocus microsatellite genotypes from 542 Texas horned lizards, Phrynosoma cornutum, using STRUCTURE for $\mathrm{K}=3$.

Each vertical line indicates the proportion of ancestry $(q)$ for an individual lizard with the colors representing the cluster or population identified in STRUCTURE. Individual lizards are organized by geographic sampling location, starting with the most western locations on the left and then moving to more northern locations and then southern locations.

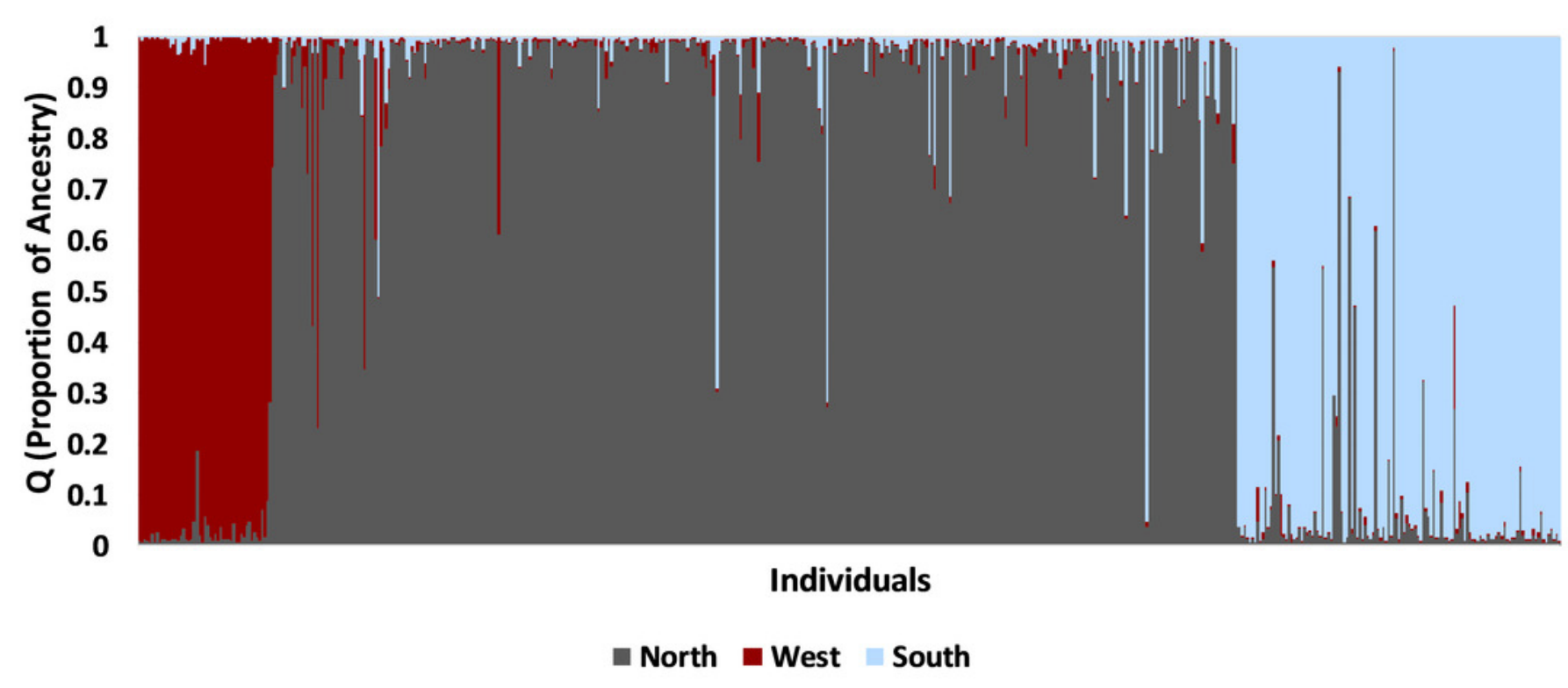




\section{Figure 5}

Maximum likelihood tree for Texas horned lizard, Phrynosoma cornutum, mitochondrial control region (353 bp) haplotypes ( $n=542$ individuals) rooted with Phrynosoma blainvillii.

Numbers at nodes are bootstrap values (bs). The tree has one well supported clade (bs $=80$ ) corresponding to western localities, with 31 individuals in the western clade and 189 individuals in the eastern clade. Colored shapes indicate the nuclear microsatellite population(s) in which a particular mitochondrial haplotype was found (see text). Red circles indicate the west population, light blue squares the south population, dark gray triangles the north population, open squares both the south and north populations, open triangles both the west and north populations, and black diamonds the west, north, and south populations. 


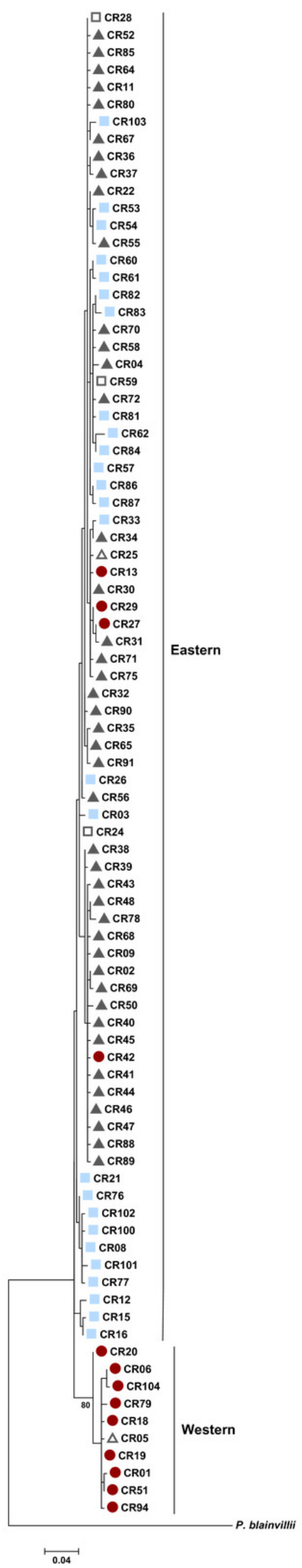

Peer) reviewing PDF | (2019:01:34651:2:0:NEW 21 Aug 2019) 


\section{Figure 6}

Maximum likelihood tree for the Texas horned lizard, Phrynosoma cornutum, ( $n=49$ individuals) based on $778 \mathrm{bp}$ of the mitochondrial NADH dehydrogenase subunit 4 (ND4) and the tRNAs Histidine, Serine, and Leucine, rooted with Phrynosoma asio.

Numbers at nodes are maximum likelihood bootstrap values/Bayesian posterior probabilities. Colored shapes indicate in which nuclear microsatellite population(s) a particular haplotype was found (see text). Red circles indicate the west population, light blue squares the south population, dark gray triangles the north population, open squares both the south and north populations, and open triangles both the west and north populations. 


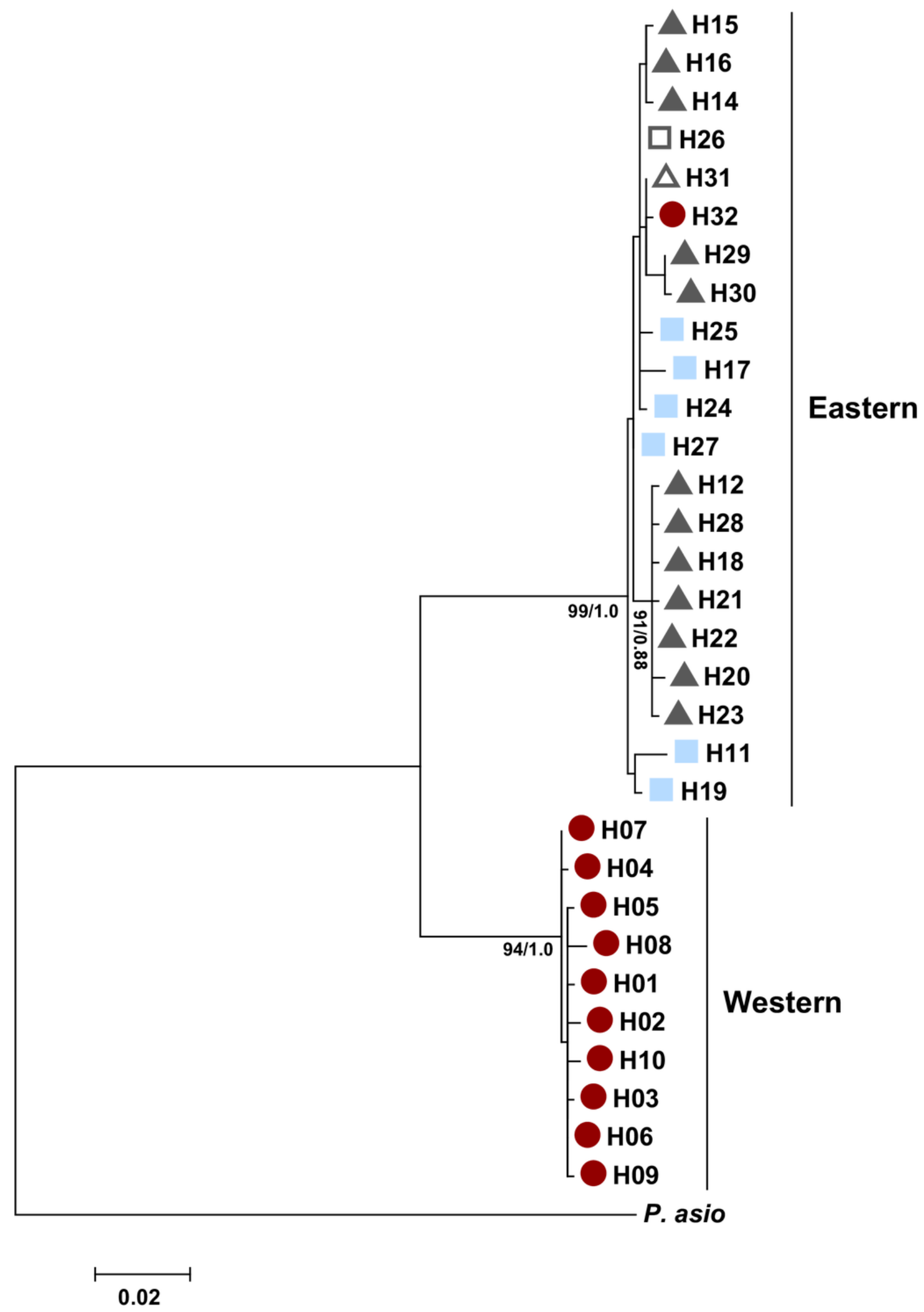

